\title{
A Brave, Unconventional Teacher: A Medical Student's Experience
}

Ibon Gantxegi Fernández.

\section{The Experience}

Disclaimer: Some names and identifying details have been changed to protect the privacy of individuals.

About the Author: Ibon Cantxegi is a third-year medical student of a six-year program at the University of the Basque Country in Leioa, Spain. He is also a Red Cross volunteer and a member of the Academy of Medical Sciences of Bilbao.

Veni is the individual to whom I owe the vast majority of my knowledge in medical anatomy. She was a true vocational educator whom I never got around to expressing enough gratitude to. She left a strong impression on us as human beings primarily, and as physicians-in-training secondarily. These words are for her, may she rest in peace.

Our earliest encounter with Veni took place at the beginning of our first semester in medicine. Laboratory class was long over; but we, the students at dissection table number four, had been working at an unhurried pace and thus were still tidying up our class materials when a conversation started between us. We were in agreement about how unrealistic plastic models were in identifying anatomical structures; at that point in our education, all the anatomy that we had been exposed to was through these plastic replicas. It was then that a bypassing member of staff heard our complaints and, instead of attempting to convince us of the value of these models, lead us to a room to see the special educator assigned to us-Veni.

Despite her physique, she was not, rather surprisingly to us, the oldest of the educators. She was slightly-built, skinny and her hair grey. Every query directed at her was always well received, and a precise answer with explicit gross anatomical imagery provided. She also managed to make every subject "come alive" with this imagery - much more so than the plastic models we were used to. We came to realize, however, that this was the first vital lesson in anatomy that we had learned from her: that even the simplest of anatomical models bore an important resemblance to reality that we ought not to overlook. Be they plastic, wooden or cadaveric, we simply had to look at models as different patients.

Ever since our first encounter with Veni, we visited her often during the long laboratory hours to share our progress with her, and she always seemed to be expecting us. Topic after the other, system by system, we soon began to realize the value of time spent with her. Soon after, most of the other student dissection groups were assigned a special educator. By then, we had all come to one conclusion; that a deep appreciation was growing in us for these people.

As our group's progress with Veni continued, a sudden turn of events occurred in early November; we found out that Veni had been diagnosed with an annuloaortic ectasia. ${ }^{1-2}$ It was later discovered that she had also suffered a cardiac arrest, but never found out the exact sequence of events preceding to or following her annuloaortic ectasia. That was the first time that we had ever prepared for a lesson with such dedication before meeting with her. Nothing could have been more motivating for us than studying a relevant clinical case, about a person we felt such affection for, to consolidate the knowledge we were acquiring. None of us wanted to lose such a unique opportunity despite the tragic circumstances. Never before had we been faced with the crudeness of illness as medical students.

Day after day, as our work in dissection moved forward, Veni was getting more and more fragile; we were all aware of it. Meanwhile, our admiration for the braveness she had; the courage to make the decisions she did, grew equally. Her skin coloration, among other physical features, was constantly worsening, showing what presumably was happening under it; but she had decided to share the details of her disease with us and nothing, not even her family and friends, had been able to change her mind. ${ }^{3}$ Veni had decided to make a life lesson for us, the medical students, from her tragedy.

As of that point in time, the circumstances made us constantly aware of the necessity to maintain a sound doctor-patient relationship-especially upon diagnosis of terminal illness. Close to Veni, we became conscious about how important it is for the patient to be accompanied by their doctor on their final walk towards destiny, and how the effects of those last moments are critical in making end-of-life decisions. Indeed, family and

Submission: Jan 25, 2016

Acceptance: May 30, 2016

Publication: Jul 27, 2016

${ }^{1}$ University of the Basque Country, Leioa, Spain. 


\section{Experience}

friends are essential when personal difficulties are dealt with, but regarding health issues, this experience made us believe that doctors have a proactive role to play in making patients aware of their medical conditions.

The end of the semester, the last days of anatomical dissection class, brought with them even more devastating findings to Veni's case. The findings suggested intestinal obstruction as a result of adhesions formed from previous abdominal scarring. After a closer look, however, it was shown to be a dozen lymphoid tumour masses. ${ }^{3}$ The masses were located all over the mesentery, with metastasis evident at several adjacent prominent lymph nodes. We were told that this was a follicular lymphoma. At that time we neither knew what that meant, nor what treatment should have been established, but with this cancer metastasis now apparent, her prognosis had now been worsened significantly.

In all actuality, we had never really known veni before her demise; nor had the other groups known their "special" educators. The truth is that these educators had been cadavers long before our semester; our classes in anatomical dissection had begun. Our collective agreement that these people, and their end of life decisions, deserved so much more recognition than the mere title of "cadaver" given to them, lead us to entitle them as "special educators". Veni, the special educator to whom we owe much, had been lying down, deceased at the morgue, for about two years before we finally met her. She was a cadaver from the very beginning.
As a result of her end-of-life decisions, likely influenced by her passionate beliefs in medical education, veni had left us her now-deceased body as a final parting gift. This offering by her was immensely inspiring to every student that heard her story, and made the learning experience more valuable than reading any textbook we had come across in anatomy. Veni gave us the opportunity to deliver our condolences through this irreplaceable experience in learning from her terminal illness even before family members could deliver their own goodbyes.

Whatever the reasons behind this unknown woman's decision to donate her body to science, the fact is that she instilled in us a new sense of respect towards patients and the medical sciences. It established in us the values that we believe we must hold as future physicians; socially responsible caretakers of health entrusted with the knowledge accumulated to do good. The final acts of selflessness by Veni, a woman who remains anonymous to us, was our first meaningful lesson in our paths to becoming future physicians.

Rest in peace, Veni. Your legacy will live on.

\section{References}

1. Hutchison SJ. Aortic diseases: clinical diagnostic imaging atlas. Philadelphia (PA): Elsevier Saunders; 2009. p. 196.

2. Tokuhiro K, Uchida Y, Kawamura K, Sakuragawa $H$, Masuhara $H$, Oosawa $H$, et al. Evaluation of annuloaortic ectasia by angioscopy and IVUS "report of 2 cases". Diagn Ther Endosc. 2000 Jul; $7(1): 35-45$.

3. Goldman L, Schafer Al. Goldman's Cecil medicine. 24th ed. Philadelphia (PA): Elsevier Saunders; 2012. p. 245-55, 828-56.

\section{Acknowledgments}

None.

Conflict of Interest Statement at Funding

The authors have no funding, financial relationships, or conflicts of interest to disclose.

Author Contributions

Conceptualization, Data collection, Data analysis and interpretation, Writing: IBF.

Cite as:

Gantxegi Fernández I. A brave, unconventional teacher: a medical student's experience. Int J Med Students. 2016 May-Aug;4(2):76-7. 